\section{Field Evaluation of Herbicide-resistant Transgenic Broccoli}

\author{
D. Waterer ${ }^{1}$, S. Lee ${ }^{2}$, and G. Scoles ${ }^{3}$ \\ Department of Plant Sciences, 51 Campus Drive, University of Saskatchewan, \\ Saskatoon, SK, S7N 5A8, Canada
}

W. Keller ${ }^{4}$

PBI/NRC,110 Gymnasium Road, Saskatoon, SK, S7N 5C3, Canada

Additional index words. Brassica oleracea var. italica, Agrobacterium, glufosinate

\begin{abstract}
This study examined the field performance and herbicide resistance of lines of broccoli (Brassica oleracea Italica Group) generated from plants transformed for resistance to the herbicide glufosinate by Agrobacterium-mediated gene transfer. Seedling vigor and vegetative growth characteristics of the first recombinant generation $\left(R_{1}\right)$ produced by selfing the transformed lines were comparable to those of the $F_{1}$ parent (cv. Cruiser) and an equivalent nontransformed $F_{2}$ line. In hand-weeded trials, marketable yields of the $R_{1}$-transformed lines were comparable to the parental line or the corresponding nontransformed $\mathrm{F}_{2}$ line. A single application of the recommended rate of the nonselective herbicide glufosinate slowed the growth and reduced yields of nontransformed broccoli, but had little effect on head quality or yields of most transformed lines. Inheritance of herbicide resistance in the $R_{1}$ progeny of the $R_{0}$ transgenic plants followed standard Mendelian ratios for a completely dominant trait controlled by a single gene. The results confirm the potential for improvement of broccoli through the incorporation of herbicide resistance by gene transfer technology. Chemical name used: 2-amino-(4hydroxymethylphosphinyl)butanoic acid (glufosinate, phosphinothricine).
\end{abstract}

The use of gene transfer technology to introduce resistance to broad-spectrum herbicides such as glufosinate (phosphinothricine) and glyphosate $[N$-(phosphonomethyl) glycine)] has revolutionized the breeding and production of oilseed brassicas such as canola (Brassica napus L.) in Canada. In 1998, the area planted to herbicide-resistant transgenic canola in Canada was almost equal to that planted to the standard types (National Research Council of Canada, 1998). The herbicide resistance traits have enhanced growers' ability to economically control emerged weeds in an established crop. Weed control is also essential to efficient production of vegetable crop brassicas such as broccoli, but few herbicides are currently approved for use on these crops. Options for control of broadleaf weeds after crop emergence are particularly limited.

Lee (1996) produced broccoli plants, cv. Cruiser, transformed for resistance to the herbicide glufosinate by Agrobacterium-mediated gene transfer. Glufosinate is a nonselective herbicide that inhibits the enzyme glutamine synthetase, resulting in accumula-

Received for publication 1 June 1999. Accepted for publication 9 Dec. 1999. The cost of publishing this paper was defrayed in part by the payment of page charges. Under postal regulations, this paper therefore must be hereby marked advertisement solely to indicate this fact.

${ }^{1}$ Associate Professor; to whom reprint requests should be addressed.E-mail:waterer@sask.usask.ca ${ }^{2}$ Former Graduate Student. Current address: Plant Biotech Research and Development Center, Dongbu Research Council, Daejon, Korea.

${ }^{3}$ Professor and Department Head.

${ }^{4}$ Director of Research. tion of ammonium and leading to the death of cells and ultimately the plant. Cotyledonary petiole explants of broccoli were transformed with a chimeric phosphinothricine acetyltransferase (PAT) gene from the bacterium Streptomyces viridochromogenes (Wohlleben et al., 1988). The PAT gene product is an enzyme that acetylates phosphinothricine, thereby inactivating it (Murakami et al., 1986). Expression of the PAT gene was controlled by a cauliflower mosaic virus $35 \mathrm{~S}$ promoter, with translational enhancer sequences obtained from the alfalfa mosaic virus (Datla et al., 1993). Transformed plants initially selected on kanamycin were assayed for the presence of the PAT gene using polymerase chain reaction (PCR) procedures and for PAT activity by enzyme assay (DeBlock et al., 1989).

This paper reports on the field performance and herbicide response of the recombinant generation $\left(R_{1}\right)$ progeny derived from broccoli plants transformed for resistance to glufosinate by Agrobacterium-mediated gene transfer.

\section{Materials and Methods}

Transgenic plants $\left(\mathrm{R}_{0}\right.$ generation $)$ of the $\mathrm{F}_{1}$ hybrid cultivar Cruiser were grown out in the greenhouse to the flowering stage. The plants were self-pollinated after the inflorescences were sprayed with $4 \% \mathrm{NaCl}$ to overcome selfincompatibility (Lee, 1996). The segregation ratios for the $B$-glucuronidase (GUS) marker gene were determined by assaying for GUS activity (Jefferson, 1987) in cotyledons collected from the $R_{1}$ seedling populations derived from the self-pollinated transgenic lines (Lee, 1996).

Field trials of the $\mathrm{R}_{1}$ seedling populations were conducted in 1995 and 1996. In 1995, six $\mathrm{R}_{1}$ lines were evaluated. In 1996, the line TCR3 , which had the best combined herbicide resistance and yield potential in the 1995 trial, was evaluated again. In both years, the parental line (cv. Cruiser) was used as a standard for evaluation of the field performance and herbicide resistance of the $\mathrm{R}_{1}$ transgenic lines. Direct comparisons between the $\mathrm{R}_{1}$ generation and the parental lines were complicated by the fact that the transformation was performed using tissue from an $\mathrm{F}_{1}$ hybrid. Consequently, the $\mathrm{R}_{1}$ generation would be genetically equivalent to an $\mathrm{F}_{2}$ and be segregating at a number of loci. To help determine whether the transformation process and the accompanying selfing significantly altered field performance, plants generated by self-pollination of 'Cruiser' were also included in the 1996 trial. Transplants of the various test lines were produced under standard greenhouse conditions. Emergence of the seedlings was evaluated $15 \mathrm{~d}$ after seeding. Seedlings were transplanted at the three to four true-leaf stage.

The field trials were conducted at the Horticulture Science Field Research Station in Saskatoon, Sask. Standard site preparation and crop management procedures for broccoli in western Canada were employed (Alberta Agriculture, 1989). Trifluralin [2,6-dinitro- $N$ $N$-dipropyl-4-(trifluoromethyl)benzenamine] was applied at $1.2 \mathrm{~L} \cdot \mathrm{ha}^{-1}$ a.i. prior to transplanting. The crop was transplanted into the field in mid-June. Plants were set $30 \mathrm{~cm}$ apart in each row with $0.75 \mathrm{~m}$ between rows in 10m-long test strips. Each row of transgenic material (six lines in 1995 and one line in 1996) was flanked by a row of nontransformed parental material (cv. Cruiser) in 1995 and by 'Cruiser' and its self-pollinated progeny in 1996. The trial was conducted using a randomized complete-block design with four replicates.

Half of each test plot was sprayed with glufosinate in mid-July, $\approx 1$ month after transplanting. At this time, the flush of weeds that had escaped the standard preplant herbicide treatment were still small enough to be effectively controlled by the herbicide and had not begun to compete with the crop. Once the crop reached the eight-leaf stage, the glufosinate was applied at the rate recommended for weed control in herbicide-resistant transgenic field crops such as canola (600 g.ha ${ }^{-1}$ a.i. in 60 $\mathrm{L} \cdot \mathrm{ha}^{-1}$ of water at $279 \mathrm{kPa}$ ). The spray effects on the broccoli were evaluated $7 \mathrm{~d}$ posttreatment. The other half of each plot was not sprayed and weeds were controlled by hand.

Each treatment was subject to a single once-over harvest at vegetative maturity (florets fully expanded, but no yellowing). The heads were weighed and evaluated for conformation (head diameter and bead color).

Growth and yield data were analyzed using the GLM procedures for SAS (SAS Institute, 1990). All percentage data were arcsin transformed prior to analysis. Mean comparisons were conducted using Fisher's LSD test at $P \leq$ 0.05 . Chi-square tests $(P \leq 0.05)$ were used to analyze the inheritance pattern of the transferred gene traits. 


\section{Results and Discussion}

Seedling performance. Segregation ratios for GUS activity for all of the $\mathrm{R}_{1}$ seedling lines matched the 3:1 ratio expected for a single dominant Mendelian locus (Table 1). All vegetative growth characteristics (percent emergence, growth rate, and form) of the $\mathrm{R}_{1}$ generation from the transgenic lines were comparable with the parental line 'Cruiser' (data not shown).

Spray reaction. Herbicide effects on the weeds were apparent within $48 \mathrm{~h}$ of application, with scorching of contacted areas followed by death of the apical meristems. Smaller weeds were killed by the spray, while growth of larger weeds was only checked. Because of their large size at the time of spraying, none of the nontransformed broccoli plants were killed outright by the herbicide application, but the herbicide scorched the leaves and damaged the apical tissues (Fig. 1), which often resulted in the formation of multiple small heads rather than the standard single, large head. There was localized spray damage on most of the transgenic lines (leaf scorch at spray contact points). A proportion of the plants subsequently developed more widespread symptoms typical of the nontransgenic lines (Fig. 1 and Table 1). The damaged transgenic plants eventually recovered and some produced marketable heads, although head size and quality were usually reduced. Chi-square tests of the ratio of damaged to nondamaged plants for the various lines also suggested a close match to a 3:1 ratio expected for a single dominant Mendelian locus (Table 1).

Yield. Application of glufosinate to the nontransformed control line (or its selfed progeny) substantially reduced marketable yields because of the combined negative effects of the herbicide on the number of plants yielding a marketable head and the average size of any marketable heads (Table 2). In 1995, marketable yields for the $\mathrm{R}_{1}$ populations in the handweeded plots were variable and generally less than those of the 'Cruiser' control. This presumably reflects the combined result of inbreeding effects and any position effect associated with transgene insertions. The effects of inbreeding depression on yield were apparent in the 1996 trial, which included both herbicide-treated and hand-weeded plots of 'Cruiser' $\mathrm{F}_{2}$ (Table 2). As a portion of each segregating population $(25 \%)$ would be expected to be nontransgenic because of segregation of the transgene, application of glufosinate to the $R_{1}$ populations was expected to reduce yields. However, TCR-24 was the only transgenic line to show a significant yield difference between the sprayed and control treatments (Table 2). Although the assays indicated that TCR-24 was transgenic (Table 1), expression of the transgene may not have as been as effective as in the other lines.

Plants in the various treatments (sprayed vs. control and transgenic vs. nontransgenic) were also evaluated for head quality parameters, such as head diameter, stem diameter, head color, and density. The $\mathrm{R}_{1}$ progenies of
Table 1. Segregation for $B$-glucuronidase (GUS) activity and resistance to foliar damage following application of glufosinate to $\mathrm{R}_{1}$ progeny of transgenic lines of broccoli.

\begin{tabular}{|c|c|c|c|c|c|c|}
\hline \multirow[b]{3}{*}{ Line } & \multicolumn{3}{|c|}{ GUS activity $^{\mathrm{z}}$} & \multicolumn{3}{|c|}{ Herbicide resistance } \\
\hline & \multicolumn{2}{|c|}{ No. of plants } & \multirow[b]{2}{*}{$\chi^{2}$ Value for $3: 1$ ratio } & \multicolumn{2}{|c|}{ No. of plants } & \multirow[b]{2}{*}{$\chi^{2}$ Value for $3: 1$ ratio } \\
\hline & Examined & GUS (+) & & Examined & Resistant & \\
\hline TCR-3 & 63 & 53 & $2.884^{\mathrm{y}}$ & 120 & 88 & 0.177 \\
\hline TCR-4 & 61 & 48 & 0.441 & 36 & 24 & 1.333 \\
\hline TCR-6 & 182 & 136 & 0.007 & 36 & 30 & 1.333 \\
\hline TCR-11 & 208 & 153 & 0.221 & 36 & 32 & 3.703 \\
\hline TCR-12 & 198 & 147 & 0.060 & 36 & 26 & 0.148 \\
\hline TCR-24 & 96 & 74 & 0.222 & 36 & 24 & 1.333 \\
\hline
\end{tabular}

${ }^{\mathrm{z}}$ Data from Lee (1996).

${ }^{\mathrm{y}} \chi^{2}$ values $<3.843$ indicate the data fit the expected ratio $(P \leq 0.05)$.

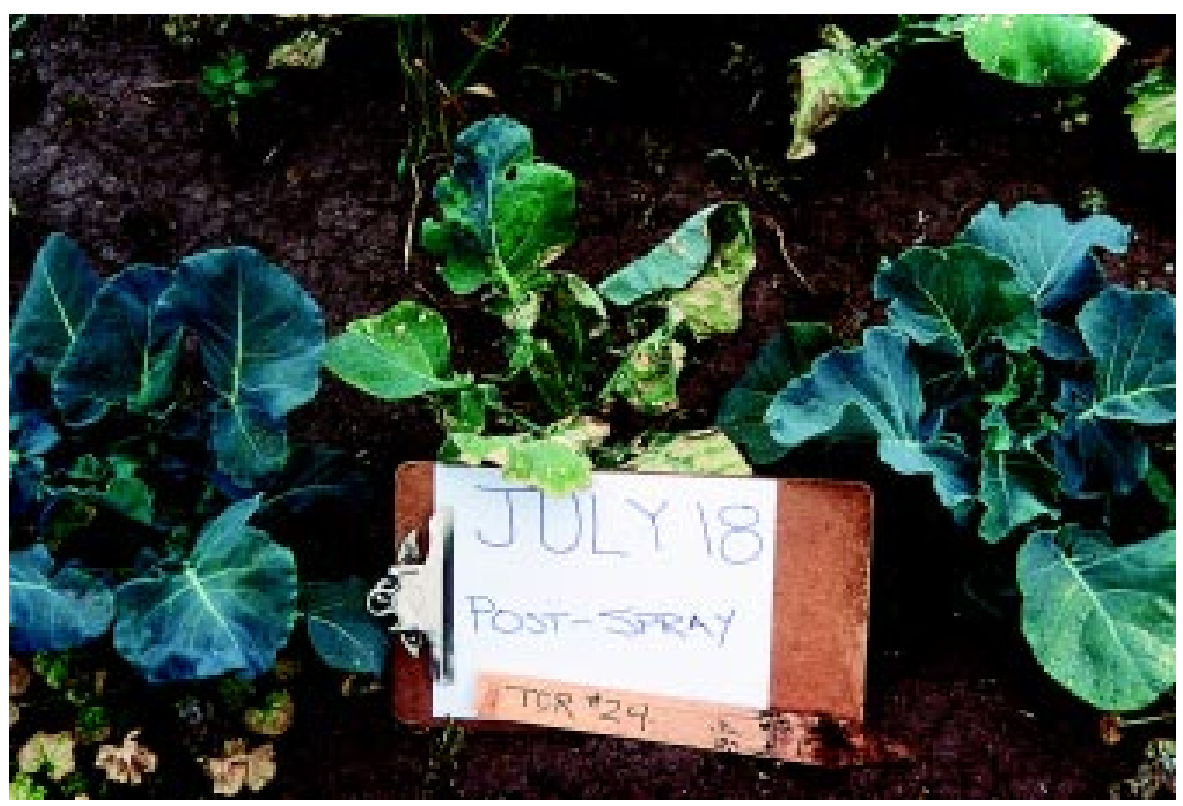

Fig. 1. Transformed $\mathrm{R}_{1}$ broccoli plants flanking a nontransformed plant at $7 \mathrm{~d}$ after application of glufosinate to the TCR-24 line.

Table 2. Yields and head characteristics of the $R_{1}$ progeny of transgenic broccoli and those of the nontransformed parental line (cv. Cruiser) or a selfed nontransformed $\mathrm{F}_{2}$ line in trials with or without the nonselective herbicide glufosinate.

\begin{tabular}{|c|c|c|c|c|c|c|}
\hline \multirow[b]{2}{*}{ Herbicide: } & \multicolumn{2}{|c|}{$\begin{array}{c}\text { Marketable } \\
\text { heads } \\
(\%)\end{array}$} & \multicolumn{2}{|c|}{$\begin{array}{c}\text { Marketable } \\
\text { yield } \\
\left(\mathrm{t}^{-h^{-1}}\right)\end{array}$} & \multicolumn{2}{|c|}{$\begin{array}{c}\text { Avg } \\
\text { head wt } \\
(\mathrm{g})\end{array}$} \\
\hline & + & - & + & - & + & - \\
\hline & \multicolumn{6}{|c|}{1995} \\
\hline Cruiser & 66 & 88 & 4 & 23.2 & 161 & 574 \\
\hline TCR-3 & 97 & 79 & 19.1 & 18.5 & 471 & 511 \\
\hline TCR-4 & 80 & 92 & 12.9 & 14.8 & 341 & 347 \\
\hline TCR-6 & 100 & 72 & 15.1 & 13.5 & 326 & 404 \\
\hline TCR-11 & 100 & 72 & 18.7 & 13.8 & 422 & 392 \\
\hline TCR-12 & 76 & 88 & 14.2 & 15.5 & 416 & 395 \\
\hline TCR-24 & 76 & 91 & 10.2 & 17.8 & 304 & 413 \\
\hline \multirow[t]{2}{*}{$\mathrm{LSD}_{0.05}$} & \multicolumn{2}{|c|}{17} & \multicolumn{2}{|c|}{8.5} & \multicolumn{2}{|c|}{183} \\
\hline & \multicolumn{6}{|c|}{1996} \\
\hline Cruiser & 31 & 82 & 2.4 & 13.6 & 66 & 334 \\
\hline Cruiser (selfed) & 12 & 70 & 0.8 & 10.5 & 78 & 303 \\
\hline TCR-3 & 74 & 78 & 12.2 & 13.5 & 331 & 337 \\
\hline $\mathrm{LSD}_{0.05}$ & \multicolumn{2}{|c|}{14} & \multicolumn{2}{|c|}{2.6} & \multicolumn{2}{|c|}{76} \\
\hline
\end{tabular}

${ }^{\mathrm{z}} \mathrm{N}=24$ for Cruiser, otherwise $\mathrm{N}=4$. 
the transgenic lines were similar to one another in appearance and were comparable to the nonsprayed parental line 'Cruiser' in head size (Table 2) and appearance. Herbicide treatment had no discernible effect on head size, color, or quality in the transgenic lines (data not shown), but greatly reduced head size in the surviving nontransformed plants (Table 2).

Changes in appearance and field performance are a common side-effect of the transformation process (McHughen and Holm, 1995). If insertion of the T-DNA impairs the function of a critical gene, appearance or performance may be adversely affected (Lee, 1996; Radke et al., 1988). Alternately, somaclonal variation occurring during the tissue-culturing process may alter the phenotype (McHughen, 1994). In this study, the seedling vigor, rate of growth and head development, and crop uniformity of the $R_{1}$ progeny from the various transformed lines were often comparable to those of the nonsprayed parental line or the equivalent nontransformed $\mathrm{F}_{2}$ line. Some of the transformed lines produced smaller than normal heads, and marketable yields of these lines were reduced correspondingly. This may reflect an adverse effect of the transformation process. However, the $\mathrm{R}_{1}$ lines being evaluated effectively represent an $\mathrm{F}_{2}$ generation, and some yield loss is expected in $\mathrm{F}_{2}$ populations. This is demonstrated by the 1996 data, where the $\mathrm{F}_{2}$ line obtained by selfing nontransformed 'Cruiser' plants yielded less than did the parental line (Table 2). Despite this expected yield depression, the yields and head size characteristics of some of the transformed lines (TCR-3 and TCR-24 in 1995, and TCR3 in 1996) were comparable to those of the nonsprayed $\mathrm{F}_{1}$ parental line (Table 2). This suggests that Agrobacterium-mediated transformation of broccoli for resistance to the nonselective herbicide glufosinate can be achieved without necessarily sacrificing other aspects of field performance. Development of parental lines homozygous for this trait could form a useful addition to a hybrid seed program.

\section{Conclusions}

Gene transfer technology has been used to introduce herbicide resistance into a wide range of field and horticultural crops. This resistance is useful if it enhances the weed control options available to growers without compromising field performance. This study has demonstrated that Agrobacterium-mediated transformation can be used to produce broccoli lines capable of tolerating the nonselective herbicide glufosinate at a dosage adequate to provide effective control of most annual weeds. In the absence of the herbicide, seedling performance, vegetative growth characteristics, and yields of the transformed $\mathrm{R}_{1}$ lines were comparable to the nontransformed $\mathrm{F}_{1}$ parent or the corresponding nontransformed $\mathrm{F}_{2}$ lines. This suggests that transformation for herbicide resistance can be achieved without excessive detrimental effects on field performance. Inheritance of herbicide resistance in the $R_{1}$ progeny of the transgenic lines followed standard Mendelian ratios for a completely dominant trait. There were no obvious differences in the appearance or level of herbicide resistance between the hemizygous and homozygous members of each $\mathrm{R}_{1}$ population. Under standard field conditions, multiple flushes of weeds would probably require multiple applications of contact herbicides like glufosinate. Tolerance of transformed lines to multiple applications or higher than normal concentrations of the herbicide should be evaluated.

\section{Literature Cited}

Alberta Agriculture, 1989. Alberta vegetable production guide 1989-1990. Alberta Agr. Agdex 250/13-1.
Datla, R.S.S., F. Bekkaoui, J.K. Hammerlindl, G. Pilat, D.I. Dunstan, and W.L. Crosby. 1993. Improved high-level constitutive expression in plants using an AMV RNA4 untranslated leader sequence. Plant Sci. 94:139-149.

DeBlock, M., D. Brouwer, and P. Tenning. 1989. Transformation of Brassica napus and Brassica oleracea using Agrobacterium tumefaciens and the expression of the bar and neo genes in the transgenic plants. Plant Physiol. 91:694701.

Jefferson, R.A. 1987. Assaying chimeric genes in plants: The GUS gene fusion system. Plant Mol. Biol. Rpt. 5:387-405.

Lee, S. 1996. Genetic transformation of broccoli and promoter tagging in Brassica species. $\mathrm{PhD}$ Diss., Dept. Crop Sci. and Plant Ecology, Univ. of Saskatchewan, Saskatoon.

McHughen, A. 1994. Assessment of the impact and performance of transgenic plants, p. 201-221. In: G. Marchall and D. Walters (eds.). Molecular biology in crop protection. Chapman and Hall, London.

McHughen, A. and F.A. Holm. 1995. Transgenic flax with environmentally and agronomically sustainable attributes. Transgenic Res. 4:3-11.

Murakami, T., H. Anzai, S. Imai, A. Satoah, K Nagaoka, and K. Thompson. 1986. The bialphos biosynthetic genes of Streptomyces hygroscopicus: Molecular cloning and characterization of the gene cluster. Mol. Gen. Genet. 205:42-50.

National Research Council of Canada, 1998. Plant Biotechnology Bul., Natl. Res. Council Canada.

Radke, S.E., B.M. Andrews, M.M. Moloney, M.L. Crouch, J.C. Kridl, and V.C. Knauf. 1988. Transformation of Brassica napus L. using Agrobacterium tumefaciens: Developmentally regulated expression of a reintroduced napin gene. Theor. Appl. Genet. 75:685-694.

SAS Institute. 1990. SAS/STAT user's guide. Vers. 6,4 th ed. SAS Inst., Cary, N.C

Wohlleben, W., W. Arnold, I. Broer, D. Hillemann, E. Strauch, and A. Puhler. 1988. Nucleotide sequence of the phosphinothricine $\mathrm{N}$ acetyltranferase gene from Streptomyces viridochromogenes Tu494 and its expression in Nicotiana tabacum. Gene 70:25-37. 